\title{
Cardiac arrest from acute hyperkalemia during liver surgery -A case report-
}

\author{
Su-Hyun Lee, Ki-Jun Kim, Chul-Ho Chang, and Sang-Baeg Heo \\ Department of Anesthesiology and Pain Medicine, Anesthesia and Pain Research Institute, Yonsei University College of Medicine, \\ Seoul, Korea
}

We experienced a case of sudden onset of hyperkalemia during liver lobectomy and this was followed by ventricular tachycardia and cardiac arrest. The main cause of this fatality is assumed to be the wide range of surgical manipulation that induced reduced hepatic blood flow and ischemic necrosis of the hepatic cells. We report here on this case and we review the relevant medical literature. (Korean J Anesthesiol 2010; 59: S124-S127)

Key Words: Hyperkalemia, Liver, Lobectomy.

Hyperkalemia has always been a problem when performing liver surgery and especially during liver transplantation. Acute hyperkalemia during liver surgery is correlated with revascularization and metabolic acidosis due to an insufficient cardiac output during the anhepatic phase [1]. Of course, other causes like excessive release of intracellular potassium can occur with tissue injury or necrosis, for example, in patients with rhabdomyolysis, tumor lysis and severe burns [2]. Yet abrupt hyperkalemia after performing a wide-range liver lobectomy has not been previously reported.

We report here on the case of a 52-year-old male who underwent liver lobectomy for hepatocellular carcinoma. A sudden onset of hyperkalemia occurred during surgery, followed by ventricular tachycardia and cardiac arrest.

\section{Case Report}

A 52-year-old, $65 \mathrm{~kg}, 162 \mathrm{~cm}$ tall male patient was admitted for hepatoma. The patient was diagnosed as having hypertension and symptomatic ventricular premature complex and he was treated with a $\beta$-blocker and an angiotensin receptor blocker. The patient had been diagnosed with chronic renal failure two years previously and he had undergone transarterial chemoembolization (TACE) for hepatocellular carcinoma two months before the present admission. A preoperative blood test showed no hyperkalemia: the $\mathrm{Na}^{+}$level was $44 \mathrm{mM} / \mathrm{L}$, the $\mathrm{K}^{+}$level was $4.6 \mathrm{mM} / \mathrm{L}$, the BUN level was $29.8 \mathrm{mg} / \mathrm{dl}$ and the creatinine level was $10.4 \mathrm{mg} / \mathrm{dl}$. His electrocardiogram (ECG) showed normal sinus rhythm.

Anesthesia was induced with $100 \mathrm{mg}$ of propofol and $50 \mathrm{mg}$ of rocuronium, and then 1.5-2 vol\% sevoflurane was used for anesthetic maintenance. Remifentanil at $0.4-1 \mu \mathrm{g} / \mathrm{kg} / \mathrm{min}$ was continuously infused intravenously. To measure the continuous arterial pressure, a 20 gauge catheter was inserted into the right radial artery, and a $7 \mathrm{Fr}$ catheter was inserted into the right internal jugular vein for measuring the central venous pressure.

Received: March 11, 2010. Revised: 1st, March 25, 2010; 2nd, June 29, 2010. Accepted: July 21, 2010.

Corresponding author: Ki-Jun Kim, M.D., Department of Anesthesiology and Pain Medicine, Anesthesia and Pain Research Institute, Yonsei University College of Medicine, 134, Sinchon-dong, Seodaemun-gu, Seoul 120-752, Korea. Tel: 82-2-2228-2411, Fax: 82-2-2227-7897, E-mail: kkj6063@yuhs.ac

(c) This is an open-access article distributed under the terms of the Creative Commons Attribution Non-Commercial License (http:// creativecommons.org/licenses/by-nc/3.0/), which permits unrestricted non-commercial use, distribution, and reproduction in any medium, provided the original work is properly cited. 
After the surgery began, the arterial blood gas analysis and the level of electrolytes were checked every two hours. The results of the arterial blood gas analysis performed at the beginning of surgery showed no hyperkalemia (Table 1).

Neither a specific inotropic drug nor a vasoconstrictor was needed to maintain a systolic blood pressure of $150-90 \mathrm{mmHg}$ and a diastolic blood pressure of $86-51 \mathrm{mmHg}$ until the fourth hour of surgery. Thereafter, phenylephrine at $1-1.5 \mu \mathrm{g} / \mathrm{kg} / \mathrm{min}$ was continuously infused to maintain a mean blood pressure above $60 \mathrm{mmHg}$. At the fifth hour of surgery, arterial blood gas analysis showed a $\mathrm{K}^{+}$level of $4.89 \mathrm{mM}$, which was in the upper normal range, so additional treatment was not performed (Table 1). In surgical field, portal triad clampings were done before resecting each segment in order to confirm the resection margin. At 6.5 hours of surgery, a sudden decrease in arterial blood pressure was observed. The curvature of the radial artery diminished and the arterial blood pressure was 80/60 $\mathrm{mmHg}$. At that time, trisegmentectomy had been completed, so the surgeon had begun suturing the muscle layer. No compression of the artery or vein was observed and the central venous pressure was $10 \mathrm{mmHg}$, which indicated there was no hypovolemic status. The phenylephrine infusion was increased to $2 \mu \mathrm{g} / \mathrm{kg} / \mathrm{min}$. QRS widening without a switching tall $\mathrm{T}$ wave was observed in the ECG, so an immediate arterial gas analysis was performed. No acidosis was observed, but the $\mathrm{K}^{+}$level was $6.44 \mathrm{mM}$. Since hemolysis of the blood sample was possible, an arterial gas analysis was conducted again after ten minutes, and the result showed that $\mathrm{K}^{+}$level had increased to $6.65 \mathrm{mM}$ (Table 1). Calcium chloride (600 mg) was infused for several minutes and magnesium sulfate $(2 \mathrm{mg}$ ) replacement was started for correcting the magnesium deficiency. As additional treatment was about to begin, a sudden onset of ventricular tachycardia was noted on the ECG.

The surgeon began chest compression and defibrillation at $200 \mathrm{~J}$ was performed twice. The cardiac arrest was thought

Table 1. Laboratory Results during the Operation

\begin{tabular}{lrrrrrr}
\hline \multicolumn{1}{c}{ Time } & $0 \mathrm{hr}$ & $+2 \mathrm{hr}$ & $+5 \mathrm{hr}$ & $+6.5 \mathrm{hr}$ & $+8 \mathrm{hr}$ & $+9 \mathrm{hr}$ \\
\hline $\mathrm{pH}$ & 7.43 & 7.40 & 7.36 & 7.31 & 6.97 & 6.91 \\
$\mathrm{PaCO}_{2}(\mathrm{mmHg})$ & 34.5 & 32.9 & 32.5 & 31.8 & 46.7 & 34.3 \\
$\mathrm{PaO}_{2}(\mathrm{mmHg})$ & 251.2 & 302.1 & 312.9 & 302.4 & 114.8 & 313.5 \\
$\mathrm{HCO}_{3}^{-}(\mathrm{mM} / \mathrm{L})$ & 22.9 & 20.2 & 18.4 & 16.3 & 10.9 & 7.0 \\
$\mathrm{BE}(\mathrm{mM} / \mathrm{L})$ & -0.4 & -3.5 & -5.7 & -8.3 & -18.8 & -23.0 \\
$\mathrm{Hb}(\mathrm{g} / \mathrm{dL})$ & 11.6 & 10.5 & 11.3 & 11.1 & 7.3 & 6.4 \\
$\mathrm{Hct}(\%)$ & 35.0 & 32.0 & 34.0 & 33.0 & 22.0 & 19.0 \\
$\mathrm{Na}^{+}(\mathrm{mM} / \mathrm{L})$ & 146.2 & 144.8 & 145.3 & 144.5 & 153.6 & 154.9 \\
$\mathrm{~K}^{+}(\mathrm{mM} / \mathrm{L})$ & 4.30 & 4.39 & 4.89 & 6.65 & 4.93 & 4.07 \\
$\mathrm{Ca}^{2+}(\mathrm{mM} / \mathrm{L})$ & 1.21 & 1.14 & 1.11 & 1.12 & 1.15 & 1.08 \\
$\mathrm{Mg}^{2+}(\mathrm{mM} / \mathrm{L})$ & 0.52 & 0.46 & 0.42 & 0.41 & 0.46 & 0.51 \\
\hline
\end{tabular}

At the $+6.5 \mathrm{hr}$ juncture, trisegmentectomy was complete. At the time of $+7 \mathrm{hr}$, a sudden onset of ventricular tachycardia occurred. BE: base-excess, Hb: hemoglobin, Hct: hematocrit. to be due to hyperkalemia; therefore twenty units of insulin and $100 \mathrm{ml}$ of $50 \%$ dextrose solution were mixed and infused continuously while $120 \mathrm{mg}$ of sodium bicarbonate was being injected as well. One mg of epinephrine was administered repeatedly before performing defibrillation using $360 \mathrm{~J}$. At 35 minutes after the initiation of cardiopulmonary resuscitation, a sinus rhythm on ECG and a systolic blood pressure of $70 \mathrm{mmHg}$ were observed for five minutes and the total administered epinephrine was $41 \mathrm{mg}$. Nevertheless, the ventricular fibrillation continued. Due to the lack of a response to $100 \mathrm{mg}$ injected lidocaine, an amiodarone infusion was started. After applying percutaneous extracorporeal support using the right femoral vein, the ECG and blood pressure appeared to stabilize, and the patient was transferred to the intensive care unit. Over 10 hours and 50 minutes of surgery, two units of packed red blood cells and $6,680 \mathrm{ml}$ of crystalloid solution were administered. The total amount of urine was $710 \mathrm{ml}$, and 1,200 $\mathrm{ml}$ of blood was lost during the surgery.

Tests conducted one hour after resuscitation showed signs of liver damage with the laboratory results of AST/ALT: 255/156 $\mathrm{IU} / \mathrm{L}, \mathrm{Na}^{+}: 152.5 \mathrm{mM}$ and $\mathrm{K}^{+}: 3.13 \mathrm{mM}$ (Table 2). The bedside transthoracic echocardiography performed in the intensive care unit showed an inadequate volume in the ventricular chamber. The patient suffered multi-organ failure under anuria conditions, and the unstable vital signs continued despite the application of percutaneous extracorporeal cardiopulmonary support. Eight hours after his arrival in the intensive care unit, the patient suffered another cardiac arrest. After the administration of atropine and epinephrine, the sinus rhythm returned briefly, but the pulse rate dropped to lower than 40 /

Table 2. Laboratory Results in the Intensive Care Unit

\begin{tabular}{lcccc}
\hline \multicolumn{1}{c}{ Time } & $+0 \mathrm{hr}$ & $+1 \mathrm{hr}$ & $+2 \mathrm{hr}$ & $+6 \mathrm{hr}$ \\
\hline $\mathrm{pH}$ & 6.95 & 7.10 & 7.03 & 6.98 \\
$\mathrm{PaCO}_{2}(\mathrm{mmHg})$ & 25.9 & 35.5 & 33.7 & 41.4 \\
$\mathrm{PaO}_{2}(\mathrm{mmHg})$ & 322.1 & 174.2 & 268.7 & 387.5 \\
$\mathrm{HCO}_{3}{ }^{-}(\mathrm{mM} / \mathrm{L})$ & 5.7 & 5.6 & 8.9 & 9.8 \\
$\mathrm{BE}(\mathrm{mM} / \mathrm{L})$ & -24.0 & -16.2 & -8.9 & -19.8 \\
$\mathrm{Hb}(\mathrm{g} / \mathrm{dl})$ & 7.5 & 5.6 & 8.4 & 7.8 \\
$\mathrm{Hct}(\%)$ & 23.0 & 17.0 & 25.0 & 23.0 \\
$\mathrm{Na}^{+}(\mathrm{mM} / \mathrm{L})$ & 155.7 & 152.5 & & \\
$\mathrm{~K}^{+}(\mathrm{mM} / \mathrm{L})$ & 3.71 & 3.13 & & 0.90 \\
$\mathrm{Ca}^{2+}(\mathrm{mM} / \mathrm{L})$ & 1.01 & 1.03 & 1.05 & 0.40 \\
$\mathrm{Mg}^{2+}(\mathrm{mM} / \mathrm{L})$ & 0.44 & 0.46 & 0.48 & \\
$\left.\mathrm{Glucose}^{2} \mathrm{mg} / \mathrm{dl}\right)$ & & 141 & 109 & \\
$\mathrm{AST}(\mathrm{IU} / \mathrm{L})$ & & 255 & 284 & \\
$\mathrm{ALT}(\mathrm{IU} / \mathrm{L})$ & & 156 & 170 & \\
$\mathrm{ALP}^{(\mathrm{IU} / \mathrm{L})}$ & & 25 & 34 & \\
\hline
\end{tabular}

The potassium level was normalized when the patient arrived into the intensive care unit. The AST/ALT level was remarkably elevated. AST/ALT: aspartate aminotransferase/alanine aminotransferase, ALP: alkaline phosphatase, BE: base-excess, Hb: hemoglobin, Hct: hematocrit. 
min. When the ECG continued to be flat, the resuscitation attempts were discontinued.

\section{Discussion}

Cases of hyperkalemia during surgery are largely attributable to three different causes. First, $\mathrm{K}^{+}$loading during surgery may occur from the administration of high- $\mathrm{K}^{+}$solutions, massive transfusions or the administration of $\mathrm{K}^{+}$releasing drug such as succinylcholine. Second, renal function disorders or decreased urine output may disrupt $\mathrm{K}^{+}$excretion. Third, intracellular $\mathrm{K}^{+}$may migrate into the plasma, causing acidosis, insulin deficiency and muscle necrosis [3]. One report indicated that hyperkalemia developed in a case with extensive muscle dissection [4].

For the patient in this case, transfusion of two units of packed red blood cells and the patient's chronic renal insufficiency might have been the contributing risk factors for the hyperkalemia. However, a sudden $2.0 \mathrm{mM}$ increase of $\mathrm{K}^{+}$can not be explained by these factors alone. Also, hemolysis was not likely to be the cause for the hyperkalemia since the transfused packed red cells had been stored in the refrigerator for only 20 days [5].

Hyperkalemia during liver surgery often occurs in the preanhepatic phase, and this causes reperfusion syndrome [6]. Radiofrequency heat conduction to hepatic cells or TACE may lead to tumor lysis syndrome. In such cases, hyperkalemia and fatal cardiac arrest may result $[7,8]$. However, although acute tumor lysis syndrome is relatively common in hematological tumors such as Burkitt's lymphoma or acute lymphatic lymphoma, it is very rarely a complication during the treatment of solid organ tumors. Single organ tumors are generally resistant to cytotoxic therapies [9].

The patient in this case study underwent TACE twice two months before the surgery. Hepatic cellular damage might have caused by one of the TACE procedures performed prior to the surgery discussed in this paper, as well being caused by the hepatic cellular ischemia due to hepatic arterial ligature during surgery. Hepatic damage and compression by surgical manipulations might cause $\mathrm{K}^{+}$to be released from the hepatic cells [10]. During liver lobectomy, the hepatic artery or portal vein is blocked to reduce hemorrhage. Animal studies have shown that hyperkalemia can be caused by blocking the hepatic blood flow [11], and possibly because $\mathrm{K}^{+}$is released from ischemic hepatic cells. Distortion of the hepatic lobes and manipulation of the liver may decrease the hepatic blood flow. $\mathrm{K}^{+}$release resulting from ischemia may have a great effect on the plasma $\mathrm{K}^{+}$levels [12]. In the case presented here, the patient underwent right lobectomy, caudate lobectomy and left wedge resection (S2/3). Severe ischemic necrosis of the remnant hepatic cells might have occurred.

In this case report, the increase of $\mathrm{K}^{+}$one hour after surgery might explain the level of the hepatic parenchyma ischemia. The patient had chronic renal failure and he was receiving no specific treatment, and the preoperative test showed that the electrolytes were in the upper normal range. The potassium released into the plasma from necrotized hepatic cells in patients with renal function failure or acidosis decreases the regulatory function [13], and extrarenal $\mathrm{K}^{+}$homeostasis is recognized as the primary mechanism for preventing the development of hyperkalemia. Patients with chronic renal failure, such as the patient in this case report, might not be able to tolerate hyperkalemia. Many cases had reported that hyperkalemia and the distensibility findings do not coincide [11]. Nevertheless, distensibility is used as the primary index for managing hyperkalemia in all patients, including those with chronic renal failure. Thus, both ECG and $\mathrm{K}^{+}$measurements immediately before surgery are recommended for the preoperative assessment of patients.

The patient in this case study had received a $\beta$-blocker and an angiotensin receptor blocker for symptomatic ventricular premature complex. The patients who receive angiotensinconverting enzyme inhibitors show no response to rennin or aldosterone stimuli [14]. According to the final analysis, since the patient in this case received an angiotensin receptor blocker, this might have been the underlying defect responsible for the hyperkalemia through an effect on potassium homeostasis.

As shown in this case report, a wide range of surgical manipulations may cause reduced hepatic blood flow and ischemic necrosis of hepatic cells during liver surgery, and all this may lead to unanticipated hyperkalemia. In cases of renal failure, the aggravation of the hyperkalemic condition may suddenly occur. Thus, anesthesiologists should be sensitive to the hematological monitoring and electrolyte abnormalities in these susceptible patients.

\section{References}

1. Xia VW, Ghobrial RM, Du B, Chen T, Hu KQ, Hiatt JR, et al. Hyperkalemia and liver transplantation predictors of hyperkalemia in the preperfusion, early postreperfusion, and late postreperfusion periods during adult liver transplantation. Anesth Analg 2007; 105: 780-5.

2. Nyirenda MJ, Tang JI, Padfield PL, Seckl JR. Hyperkalemia. BMJ 2009; 339: b4114.

3. Alfonzo AV, Isles C, Geddes C, Deighan C. Potassium disordersclinical spectrum and emergency management. Resuscitation 2006; 70: 10-25.

4. Das SC, Pandia MP, Sharma MS. intra-operative hyperkalemia following extensive muscle dissection. Anaesthesia 2008; 63: 322-3.

5. Miller RD. Anesthesia. 7th ed. USA, Churchill Livingstone. 2009, p 1745 . 
6. Aggarwal S, Kang Y, Freeman JA, Fottunato FL, Pinsky MR. Postreperfusion syndrome: cardiovascular collapse following hepatic reperfusion during liver transplantation. Transplant Proc 1987; 19: 54-5.

7. Lehner SG, Gould JE, Saad WE, Brown DB. Tumor lysis syndrome after radiofrequency ablation of hepatocellular carcinoma. AJR Am J Roentgenol 2005; 185: 1307-9.

8. Akahane M, Koga H, Kato N, Yamada H, Uozumi K, Tateishi R, et al. Complications of percutaneous radiofrequency ablation for hepato-cellular carcinoma: imaging spectrum and management. Radiographics 2005; 25 Suppl 1: S57-68.

9. Kalemkerian GP, Darwish B, Varterasian ML. Tumor lysis syndrome in small cell carcinoma and other solid tumors. Am J Med 1997;
103: 363-7.

10. Kaku R, Matsumi M, Fujii H, Ohashi I, Mizobuchi S, Katayama H, et al. A case of severe acute hyperkalemia during pre-anhepatic stage in living-related liver transplantation. Masui 2002; 51: 1003-6.

11. Stewart JD, Potter WH, Hubbard RS, Andersen MN. Potassium movement in acute liver damage. Ann Surg 1953; 138: 593-9.

12. Silver IA. Ion fluxes in hypoxic tissues. Microvasc Res 1977; 13: 40920.

13. Bercovitch DD, Davidman M, Licher M. Hyperkalemia provoked by acute hepatic necrosis. Am J Nephrol 1986; 6: 296-301.

14. Kee CS, Choi JW, Chang DK, Ahn YH, Kim HJ. Hyperkalemia due to hyporeninemic hypoaldosteronism with liver cirrhosis and hypertension. J Korean Med Sci 1993; 8: 464-70. 